\title{
Succinate dehydrogenase SDH1-1 positively regulates cotton resistance to Verticillium dahliae through a salicylic acid pathway
}

ZHANG Xiangyue ${ }^{1 \dagger}$, FENG Zili ${ }^{1 \dagger}$, ZHAO Lihong ${ }^{1}$, LIU Shichao ${ }^{1}$, WEI Feng ${ }^{1,2}$, SHI Yongqiang ${ }^{1}$, FENG Hongjie ${ }^{1,2^{*}}$ and ZHU Heqin ${ }^{1,2^{*}}$

\begin{abstract}
Background: Verticillium wilt, caused by the soil-borne fungus of Verticillium dahliae Kleb., is one of the most devastating diseases of cotton. The complex mechanism underlying cotton resistance to Verticillium wilt remains uncharacterized. Identifying an endogenous resistance gene may be helpful to control this disease. Previous studies revealed that succinate dehydrogenase $(\mathrm{SDH})$ is involved in reactive oxygen species (ROS)-induced stress signaling pathway that is likely to be triggered by salicylic acid (SA). Here, through the metabolomics and differential expression analyses in wilt-inoculated cotton (Gossypium hirsutum), we noticed that GhSDH1-1 gene in cotton may play an important role in the resistance to $\mathrm{V}$. dahlia. Then we reported GhSDH1-1 gene and its functional analysis in relation to the resistance of cotton to $V$. dahliae.

Results: The GhSDH1-1 gene in cotton root was significantly up-regulated after $\mathrm{V}$. dahlia inoculation, and its expression level peaked at 12 and $24 \mathrm{~h}$ post-infection. SA can also induce the up-regulation of GhSDH1-1. Additionally, the functional analysis showed that GhSDH1-1-silenced cotton was more susceptible to $\mathrm{V}$. dahliae than the control because of the significant decrease in abundance of immune-related molecules and severe damage to the SA-signaling pathway. In Arabidopsis thaliana, high expression of GhSDH1-1 conferred high resistance to V. dahliae. Arabidopsis that overexpressed GhSDH1-1 had higher resistance to $\mathrm{V}$. dahliae infection compared with the wild-type.
\end{abstract}

Conclusions: Our findings provide new insights into the role of GhSDH1-1; it positively regulates cotton resistance to Verticillium wilt. The regulatory mechanism of GhSDH1-1 is closely related to SA-related signaling pathway.

Keywords: Cotton, Verticillium wilt, Resistance gene, GhSDH1-1, Salicylic acid

\section{Background}

Cotton is a globally important economic crop and its fiber is an important textile to economies and people's livelihoods (Chen et al. 2007; Egbuta et al. 2017). Unfortunately in China, more than 200 million hectares of

\footnotetext{
*Correspondence: fenghongjie@caas.cn; heqinanyang@163.com

'Zhang XY and Feng ZL contributed equally to this work.

'State Key Laboratory of Cotton Biology, Institute of Cotton Research of Chinese Academy of Agricultural Sciences, Anyang 455000, Henan, China Full list of author information is available at the end of the article
}

cotton are infected by Verticillium wilt, causing serious economic losses (Erdogan et al. 2006; Malik et al. 2014). Verticillium wilt is caused by the soil-borne fungus Verticillium dahliae Kleb (Yan et al. 2016). As the most destructive soil-borne disease to cotton growth, $V$. dahliae infects individuals through the root and causes wilting, discoloration, necrosis, defoliation, and ultimately causes plants to death. Consequently, the fungus seriously threatens cotton yield and fiber quality (Gerik and Huisman 1998; Xu et al. 2011; Jiménez-Díaz et al. 2012).

(c) The Author(s). 2020 Open Access This article is licensed under a Creative Commons Attribution 4.0 International License, which permits use, sharing, adaptation, distribution and reproduction in any medium or format, as long as you give appropriate credit to the original author(s) and the source, provide a link to the Creative Commons licence, and indicate if changes were made. The images or other third party material in this article are included in the article's Creative Commons licence, unless indicated otherwise in a credit line to the material. If material is not included in the article's Creative Commons licence and your intended use is not permitted by statutory regulation or exceeds the permitted use, you will need to obtain permission directly from the copyright holder. To view a copy of this licence, visit http://creativecommons.org/licenses/by/4.0/ 
Verticillium dahliae has a wide range of hosts, and in its dormant form, micro-sclerotium, is strongly resistant to environmental stresses. It inhabits the soil all the year round and can invade and occur in various growth stages of cotton, and thus it is difficult to control (Shaban et al. 2018). In agricultural production, the prevention and control of Verticillium wilt of cotton faces severe challenges caused by difficulties in implementing crop rotation, which leads to continuouscropping of cotton in fields and results in high numbers of the pathogen in soils, as well as the lack of resistant cotton varieties and effective fungicides (Cai et al. 2009; Malik et al. 2014). Long-term production practices have shown that the search for the key genes for disease resistance in cotton is essential for managing Verticillium wilt (Cai et al. 2009). Recent studies have identified some key genes for resistance of cotton Verticillium wilt, such as GbVIP1 gene and GbTRP1 gene, which can regulate cotton resistance through positive and negative regulation, respectively (Zhang et al. 2019; Miao et al. 2019).

Complex II [succinate dehydrogenase (succinate-ubiquinone oxidoreductase); EC 1.3.5.1] is the only enzyme shared by both the tricarboxylic acid (TCA) cycle and electron transport chain in mitochondria (Huang and Millar 2013). Succinate dehydrogenase (SDH) usually consists of four subunits, flavoprotein (SDH1), ironsulfur (Fe-S) protein (SDH2) and two small integral membrane proteins (SDH3 and SDH4). These four classical SDH1-4 subunits form a natural complex, which could catalyzes the oxidation of succinate to fumarate in the mitochondria matrix and transfers electrons to ubiquinone (Tretter et al. 2016; Huang et al. 2019). As a highly conserved protein, SDH is involved in mitochondrial oxidative phosphorylation and is a major source of ATP production in aerobic eukaryotic cells. In both mammalian and plant systems, the mitochondrial reactive oxygen species (mtROS) was a significant production of SDH, and the specific SDH inhibitors suppressed the ROS production, then impairing plant growth (Gleason et al. 2011; Ralph et al. 2011; Quinlan et al. 2012; Chouchani et al. 2014; Jardim-Messeder et al. 2015; Huang et al. 2016). A study using Arabidopsis SDH1 mutants $d s r 1$ and sdhaf2 revealed that mutating SDH1 can reduce SDH activity, demonstrated a higher susceptibility to specific bacterial and fungal pathogens by disrupting the ROS-induced stress salicylic acid (SA) signaling pathway (Gleason et al. 2011; Belt et al. 2017; Huang et al. 2019). Although these studies indicate that SDH has an important relationship with plant disease resistance, it is not clear whether SDH is involved in the cotton resistance mechanism and how SA may interact with SDH to produce mtROS in cotton. A more comprehensive characterization of cotton SDH function may contribute to the breeding of cotton varieties resistant to Verticillium wilt.

Plants evolves defense mechanisms to identify and resist the infection of pathogens, including constitutive defense systems and inducible defense systems (Daayf 2015; Shaban et al. 2018). In the process of plant interaction with pathogens, a series of signals are transmited through plant signal molecules, such as reactive oxygen species (ROS), SA, jasmonic acid (JA), nitric oxide (NO), etc. They play an important role in regulating defense signaling networks and stimulating plant defense systems, enabling plants to develop disease-resistant responses (Chen et al. 1993; Moreau et al. 2012; Shaban et al. 2018). SA is an important signaling molecule. Once the SA pathway is activated at the site of infection, it usually triggers a defense response in distal plant parts to protect undamaged tissues. This long-lasting broadspectrum sensing resistor is called system-acquired resistance (SAR) (Norman et al. 2004; Häffner et al. 2014; Verma et al. 2016). In addition, elevated levels of SA in pathogen-exposed tissues trigger the NON-EXPRESSOR OF PR GENE 1 (NPR1), leading to the expression of PATHOGENESIS RELATED (PR) genes and subsequent defense responses (Grant and Lamb 2006; Fu et al. 2012). The activation of plant immune responses is also associated with increases in the production of reactive oxygen intermediates and NO levels (Nie et al. 2015; Caarls et al. 2015). These complex signaling molecules and signal transduction networks provide plants with powerful means of regulating immune responses (Fradin et al. 2009; Li et al. 2011; Cheng et al. 2016).

In this study, we identified $18 \mathrm{SDH}$ genes in cotton and found that four SDH1 genes (GhSDH1-1, GhSDH12, GhSDH1-3, GhSDH1-4) were up-regulated after infection. Especially, the expression levels of SDH1-1 peaked at 6 and $12 \mathrm{~h}$ after infection. Silencing this gene compromised cotton resistance and weakened SA signaling pathway. In contrast, overexpression of GhSDH1-1 conferred resistance to pathogen infection in Arabidopsis plants. Our results provide important evidence illustrating that SDH positively regulates cotton resistance to Verticillium wilt through the SA signaling pathway.

\section{Results}

Analysis of GhSDH1-1 structure and expression patterns in cotton treated with $V$. dahliae or salicylic acid

Based on the results of an unpublished metabolomics analysis of disease responses in cotton, the metabolite succinic acid content decreased and the fumaric acid content increased after inoculation (Additional file 1: Figure S1). The two substances were regulated by SDH, which can convert succinic acid into fumaric acid. Succinate dehydrogenase consists of four classical subunits and several accessory subunits and assembly factors 
(Huang and Millar 2013). We used the SDH protein sequence of Arabidopsis to compare with that of G. hirsutum plants and identified 18 genes (the homology analysis of these genes are shown in Additional file 1: Figure S2). To further investigate the function of these genes, RT-qPCR analysis was performed to detect the expression of the SDH gene in roots of inoculated cotton (Fig. 1). The results showed that the genes of SDH1 subunit (GhSDH1-1, GhSDH1-2, GhSDH1-3, GhSDH1-4) were up-regulated obviously after infection. Especially, the expression level of GhSDH1-1 peaked at 6 and $12 \mathrm{~h}$ after infection. This may be play an important role in cotton defense responses to $V$. dahliae infection.

To identify the signaling pathway associated with GhSDH1-1, we examined the GhSDH1-1 expression pattern in hormone (SA)-treated 'Zhongzhimian 2' plants. The expression of GhSDH1-1 was rapidly induced and peaked at $6 \mathrm{~h}$ after treatment. In addition, a lower SA concentration induced a higher level of
GhSDH1-1 expression (Fig. 2a). These results suggested that GhSDH1-1 enhanced the resistance of cotton to $V$. dahliae and affected the SA-mediated signaling pathway.

\section{Silencing of GhSDH1-1 in cotton suppressed the resistance to $V$. dahliae}

To clarify the function of GhSDH1-1 in cotton responses against $V$. dahliae, we generated GhSDH1-1knockdown plants by TRV-based virus-induced gene silencing (VIGS). At approximately 2 weeks postinfiltration, the positive contrast TRV-PDS plants started to display the albino phenotype in the true leaves. Additionally, we used qRT-PCR to assess gene-silencing efficiency. The abundance of GhSDH1-1 transcripts was significantly lower in TRV:GhSDH1-1 plants than that in the controls (Fig. 2b, c), indicating that GhSDH1-1 was effectively silenced in these plants. Furthermore, after $V$. dahliae inoculation, disease symptoms were not visually apparent on the tissues of control plants, while necrotic, yellowish, stunted, and wilting leaves were observed on

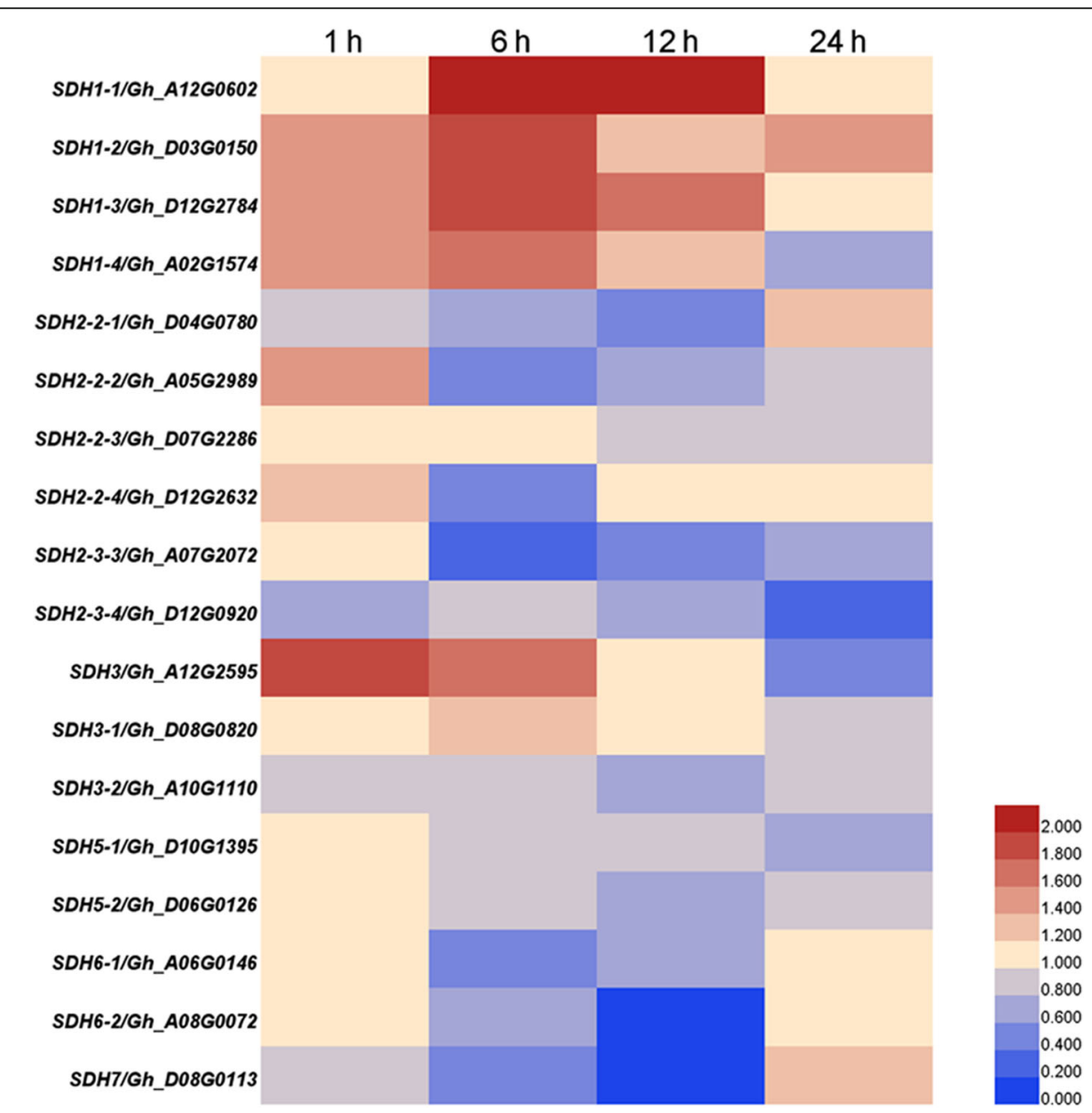

Fig. 1 Expression patterns of GhSDH1-1 under Verticillium dahliae stress treatment in cotton. The cotton 'Zhongzhimian 2' were treated with Verticillium dahliae (Vd080) or an equal amount of sterile water, and the mock and treated roots were harvested at 0, 6, 12, 24 h post inoculation (hpi), respectively. The expression levels were determined by QRT-PCR, and the expression level of the mock control was normalized to ' 1 ' 

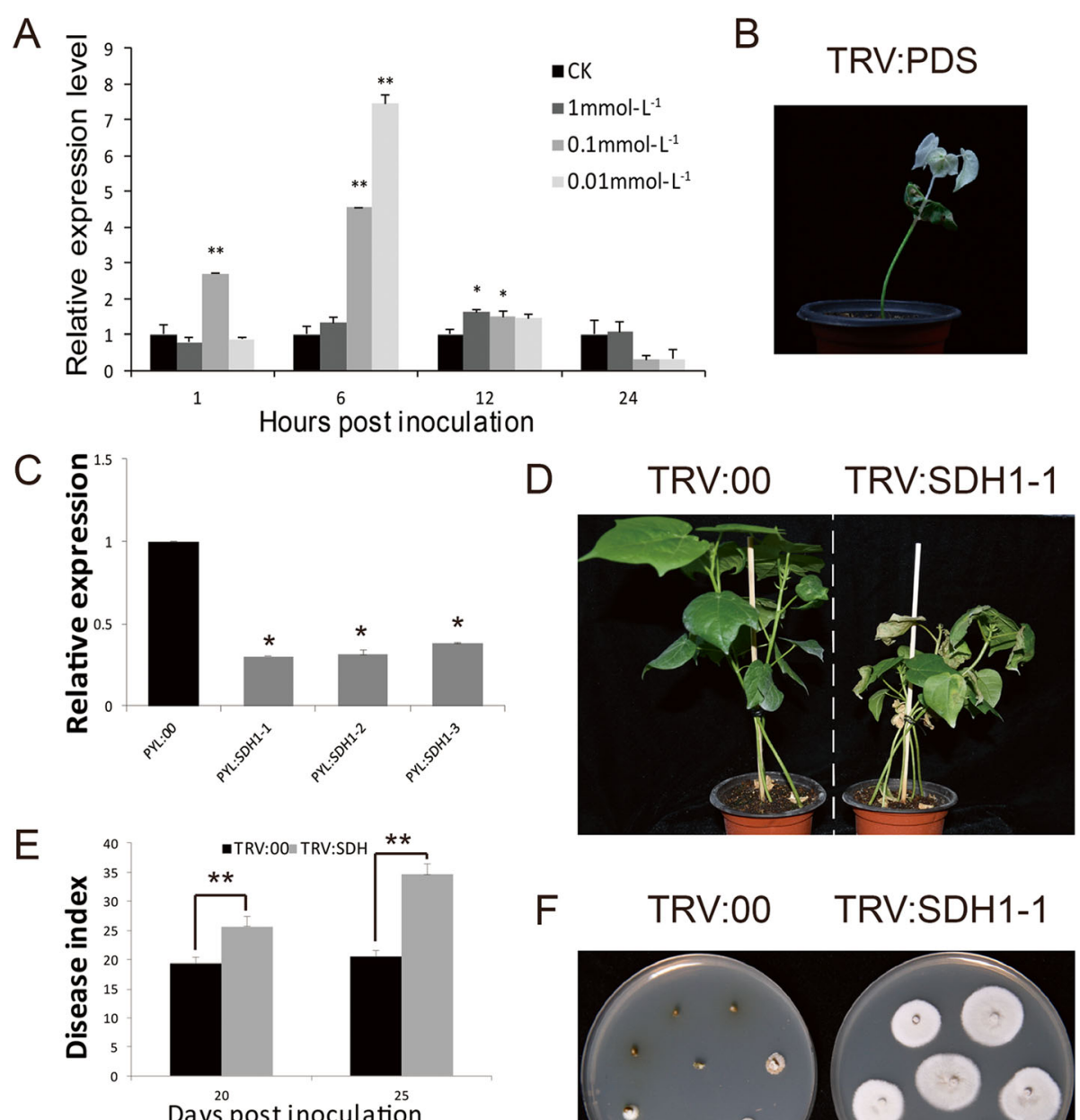

F TRV:00 TRV:SDH1-1
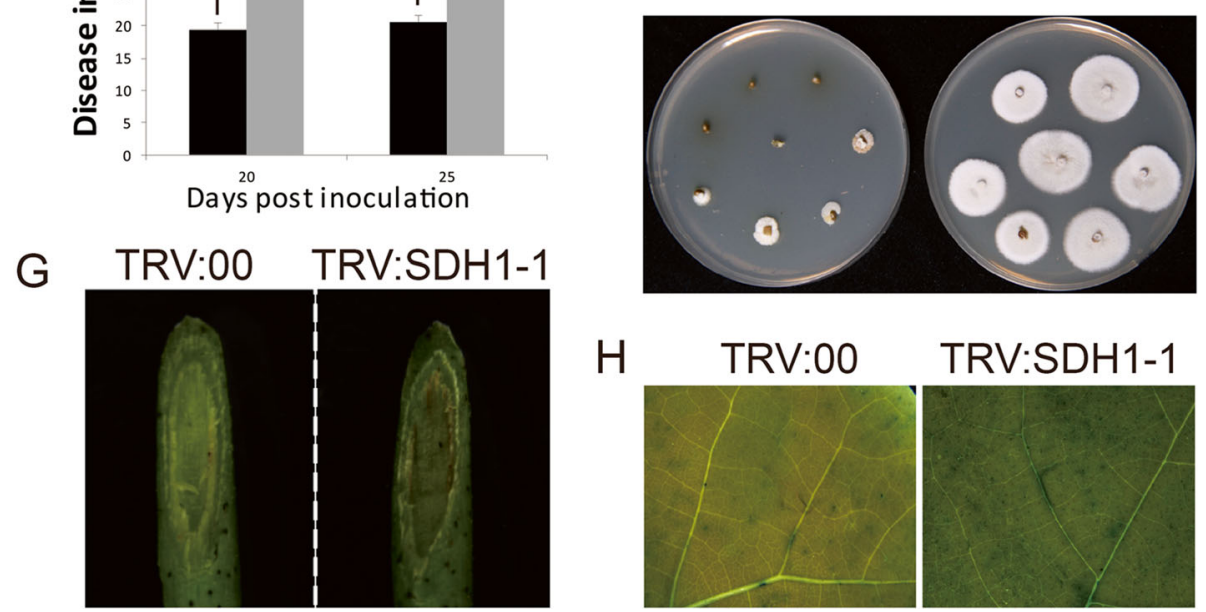

Fig. 2 a GhSDH1-1 expression pattern in hormone (SA)-treated 'Zhongzhimian 2' plants. a, Treatment with exogenous hormone SA (1 mmol.L ${ }^{-1}$, $0.1 \mathrm{mmol} \cdot \mathrm{L}^{-1}, 0.01 \mathrm{mmol} \cdot \mathrm{L}^{-1}$ ) or an equal amount of sterile water. Mimetics and treated roots were harvested at 1, 6, 12, 24 hpi, respectively, and expression levels were determined by qRT-PCR. The expression level of the simulated control was normalized to '1'. Silencing of GhSDH1-1 seriously compromises Verticillium wilt resistance in cotton. b, TRV:PDS as the visual marker for silencing efficiency. Albino phenotype appeared on TRV:SDH1-1 plants. $\mathbf{c}$, Relative transcript levels in control and TRV:SDH1-1 plants $15 \mathrm{~d}$ after hand-infiltration. $\mathbf{d}$, Disease symptoms induced with V. dahliae on control and TRV:SDH1-1 plants at $20 \mathrm{dpi}$ and $25 \mathrm{dpi}$. e, Assessment of DI for TRV:SDH1-1 plants at 20 dpi and 25 dpi. f, Verticillium dahliae recovery assay. $\mathbf{g}$, Vascular browning found in xylem from infected plants at $25 \mathrm{dpi}$. $\mathbf{h}$, Trypan blue staining. Error bars represent the standard deviation of three biological replicates. Asterisks indicate statistically significant differences as determined by Student's $t$ test $\left({ }^{*} P<0.05 ;{ }^{* *} P<0.001\right)$

TRV:GhSDH1-1 plants. The DI of TRV:GhSDH1-1 plants was significantly higher than that of the control at 20 and 25 days post-inoculation (Fig. 2 d, e). The results confirmed that the resistance of cotton plants to $V$. dahliae was compromised because of the absence of GhSDH1-1 expression.

In order to study the degree of colonization of $V$. dahliae in the stem of infected plants, the recovery assay 
showed that the number of fungi on TRV:GhSDH1-1 was significantly higher than that of control. In addition, the xylem of TRV:GhSDH1-1 plants showed greater vascular browning than that of the controls (Fig. 2f, g). To visually compare the differences in plant leaves inoculated with $V$. dahliae, we stained dead cells with trypan blue. The trypan blue stained area was larger and the color was stronger in TRV:GhSDH1-1 leaves than in control leaves (Fig. 2h).

\section{Silencing of GhSDH1-1 attenuated the expression of resistance-related genes}

To further elucidate the effect of GhSDH1-1 on Verticillium wilt resistance in cotton plants, we compared the expression levels of disease-related genes in silenced plants with control inoculated with $V$. dahliae and sampled at different times. The genes of the enzymes peroxidase (POD), polyphenol oxidase (PPO) and phenylalanine ammonia lyase (PAL) are involved in lignin synthesis. When not vaccinated, the gene expression of TRV:GhSDH1-1 plants was similar to that of the control or even higher than that of the control. However, at $1,3,6,12,24$, and $48 \mathrm{~h}$ after inoculation, the responses of these genes to $V$. dahliae infection were significantly disrupted in the TRV:GhSDH1-1 plants, and the difference was greatest at $24 \mathrm{~h}$ (Fig. 3). The expression level of HIN (HR maker gene) and JAZ (JA signaling pathwayrelated gene) were significantly decreased in the TRV: GhSDH1-1 plants (Fig. 3).

Salicylic acid pathways are important signaling pathways in plant disease resistance. We examined the expression levels of SA signaling pathway-related genes, including those involved in SA biosynthesis, such as non-expressor of pathogenesisrelated genes 1 (NPR1), pathogenesis-related gene 1 (PR1), and pathogenesisrelated gene 3 (PR3). After inoculation, the expression levels of NPR1, PR1 and PR3 in TRV:GhSDH1-1 plants were significantly weakened. The evidence suggested that silencing of GhSDH1-1 greatly attenuated the expression of resistance-related genes, such as the lignin synthesis-related genes. Consequently, significant effects occurred on the SA biosynthesis signal transduction pathway (Fig. 3).

\section{Salicylic acid, nitric oxide and $\mathrm{H}_{2} \mathrm{O}_{2}$ decreased in GhSDH1-1-silenced cotton plants upon V. dahliae infection}

To further evaluate the role of GhSDH1-1 and its relationship with the SA pathway in cotton defense responses to $V$. dahliae infection, we analyzed the abundance of fumaric acid, SA and several other immune-responsive compounds $\left(\mathrm{NO}, \mathrm{H}_{2} \mathrm{O}_{2}\right)$ in silenced and control plants. We observed a decrease in fumaric acid content GhSDH1-1-silenced plants (Fig. 4a). The content of SA in TRV:GhSDH1-1 plants was also significantly reduced compared with that of control plants (Fig. 4b). Reactive oxygen is considered an important indicator of plant disease resistance. The results showed that the content of $\mathrm{H}_{2} \mathrm{O}_{2}$ in silenced plants was lower than that of the control within the first hour after inoculation, while the content of $\mathrm{NO}$ in silenced plants increased first and then decreased compared with that of control plants (Fig. 4c, d). Furthermore, we observed the physical occurrence of reactive oxygen species by diaminobenzidine (DAB) staining in cotton leaves $24 \mathrm{~h}$ after inoculation. The DAB-stained area was large and the color was intense in the silenced plant leaves, while there was no obvious staining in control leaves (Fig. 4e). These results indicate that silencing GhSDH1-1 in wiltresistant cotton plants inhibits $V$. dahliae-induced production of $\mathrm{SA}, \mathrm{NO}$ and $\mathrm{H}_{2} \mathrm{O}_{2}$, further confirming that GhSDH1-1 is closely related to the SA signaling pathway.

\section{Overexpression of GhSDH1-1 in transgenic Arabidopsis plants enhanced $V$. dahliae resistance}

To further detect whether GhSDH1-1 confers resistance to $V$. dahliae, an overexpression strategy in Arabidopsis plants was used. The GhSDH1-1 gene was inserted into the pCAMBIA2300 plant vector and infected into $A$. thaliana ecotype Col- 0 . Two methods were used to select homozygous GhSDH1-1-overexpressing transgenic lines, including a $0.1 \%$ Kanamycin-screening and qPCR (Additional file 1: Figure S3). Two lines (line2 and line3) with the highest expression level of GhSDH1-1 were chosen for further analysis. Transgenic and WT plants were subjected to $V$. dahliae infection. Fourteen days after inoculation, WT plants showed more serious yellowing and wilting than transgenic plants (Fig. 5a, b). The disease indexes of line 2 and line 3 were 16.3 and 11.7 , respectively, which were significant lower than that of control line (Fig. 5c). This further confirms that the transgenic $A$. thaliana plants overexpressing GhSDH1-1 were more resistant to Verticillium wilt than the WT plants.

\section{Subcellular localization of GhSDH1-1}

To gain direct evidence for Gh SDH1-1 subcellular localization, the full length of SDH1-1 gene was cloned into the vector pBin-GFP, and constituted the transient expression vector SDH1-1-GFP. Mt-rk is a mitochondrial marker gene for mitochondria as a positive control. The fluorescence was observed by confocal laserscanning microscopy. The results showed that a spotty distribution of the green fluorescence of SDH1-1-GFP in the cytoplasm, and the red fluorescence of the mitochondrial marker mt-rk was punctate and elongated (Fig. 6). In addition, agrobacterium cells containing 

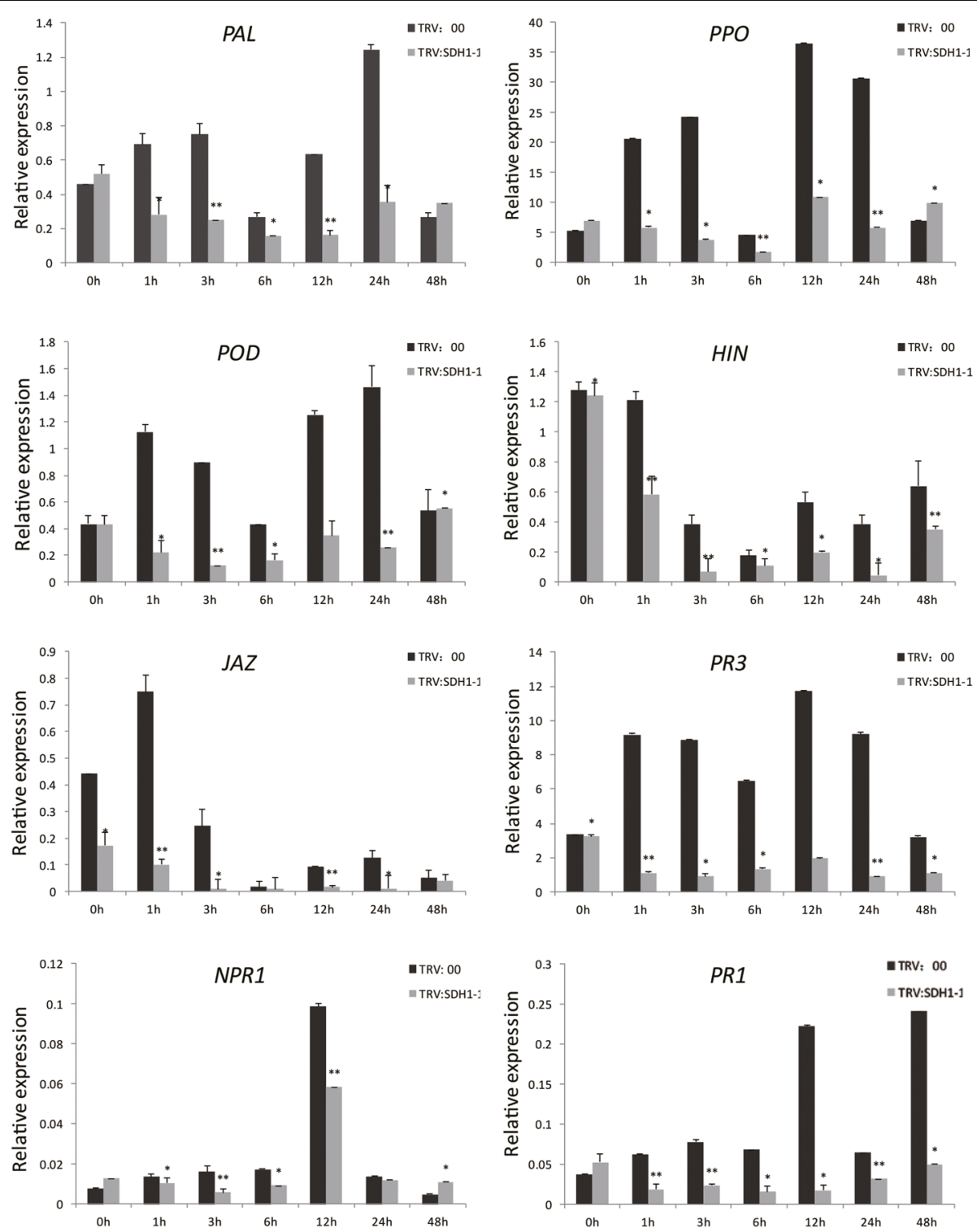

Fig. 3 Detection of expression levels of disease resistance-related genes in GhSDH1-1-silenced and control cotton plants. Total RNAs were extracted from GhSDH1-1-silenced and control cotton plants after treatment with $\mathrm{V}$. dahliae, and roots were harvested at 0, 1, 3, 6, 12, 24, and 48 hpi, respectively. The expression levels of resistance-related genes were determined by qRT-PCR. Error bars represent the standard deviation of three biological replicates. Asterisks indicate statistically significant differences, as determined by Student's t-test $\left({ }^{*} P<0.05\right.$; $\left.{ }^{* *} P<0.001\right)$

SDH1-1-GFP and mt-rk were co-infiltrated into $N$. benthamiana leaves. Indeed, the SDH1-1 protein localizes to mitochondria.

\section{Discussion}

In recent years, in-depth studies of genomics, transcriptomics and proteomics have laid the foundation for the analysis of cotton candidate genes and regulatory mechanisms for Verticillium wilt and other diseases, with the ultimate aim of generating disease-resistant cultivars by molecular breeding. In recent years, cotton leaf curl disease $(\mathrm{CLCuD})$ is also a severe disease of cotton.
It caused destructive damage to cotton production in Pakistan and India (Sattar et al. 2013). Some genes involved in cotton defense responses have been identified. For example, the key role of the thioredoxin-encoding gene GbNRX1 in $V$. dahliae infection is associated with homeostasis of apoplastic reactive oxygen species ( $\mathrm{Li}$ et al. 2016; Zhou et al. 2018). The ribosomal protein GaRPL18 (Gong et al. 2017) regulates cotton resistance to Verticillium wilt through a SA signaling pathway. However, the development of these genes for treatment is still far from adequate. Recent research showed that the identification of cotton earlier resistance genes is 

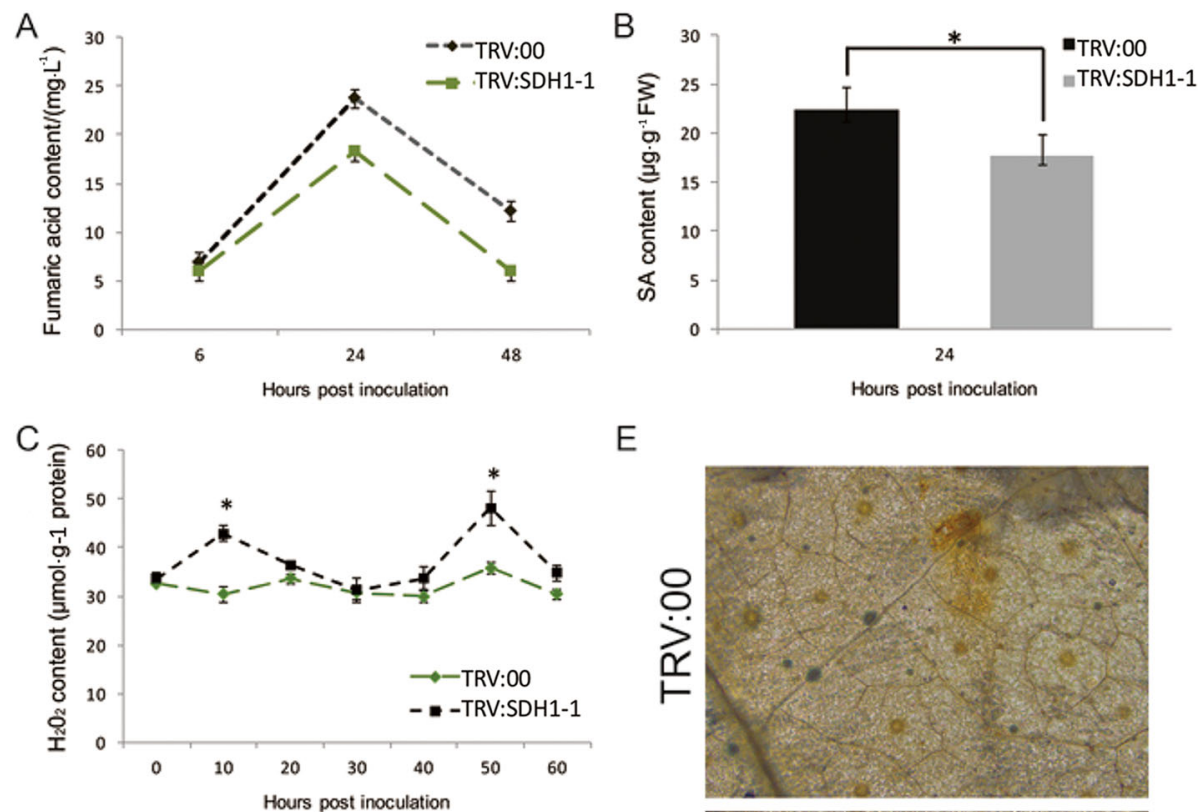

E
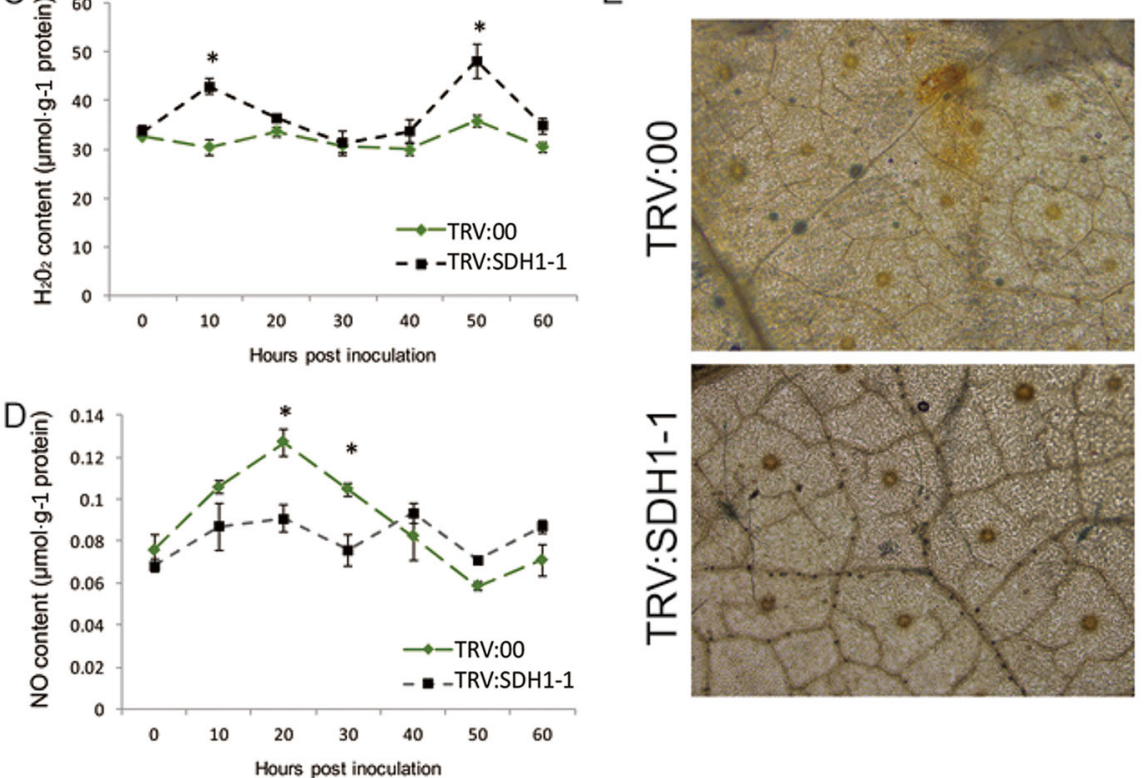

Fig. 4 The abundance of fumaric acid, $\mathrm{SA}$ and several other immune-responsive compounds $\left(\mathrm{NO}, \mathrm{H}_{2} \mathrm{O}_{2}\right)$ in $V$. dahliae treated silencing and control plants. $\mathbf{a}$, The abundance of fumaric acid. $\mathbf{b}$, The abundance of SA. $\mathbf{c}$, d the content of $\mathrm{H}_{2} \mathrm{O}_{2}$ and NO in GhSDH1-1-silenced and control cotton plants within $1 \mathrm{~h}$ after inoculation. e, Diaminobenzidine (DAB) staining to the plants at inoculation $24 \mathrm{hpi}$

one of the most effective ways to prevent the disease. When cotton is attacked by pathogens, it first generates hormone signals and then activates a series of resistance responses, such as the elicitation of PR genes, production of phytoalexins, and reinforcement of cell wall. The discovery of early resistance genes is critical to the development of new varieties of disease-resistant cotton. In the present study, we demonstrated that GhSDH1-1 encoding SDH affects resistance to Verticillium wilt. And as an early resistance gene, it is likely to have an important resistance not only in cotton resistance to Verticillium wilt, but also in cotton resistance to leaf curl disease.

As a highly conserved protein, SDH has been thoroughly researched in mitochondrial oxidative phosphorylation and production of ATP in aerobic eukaryotic cells. Moreover, recent in-depth studies report that SDH also has important roles for mtROS production in both mammalian and plant systems (Yankovskaya et al. 2003; Quinlan et al. 2012). Complex II generates ROS in both the forward reaction, with electrons supplied by succinate, and the reverse reaction, with electrons supplied from the reduced ubiquinone pool (Quinlan et al. 2012). The Arabidopsis SDH1 mutants dsr1 and sdhaf2 showed that $\mathrm{SDH}$ is involved in a ROS-induced stress signaling pathway that is likely to be triggered by SA (Gleason et al. 2011; Belt et al. 2017). These evidences suggest that SDH plays an important role in plant disease resistance and may be associated with the SA signaling pathway. Our study results also indicate that the SDH gene plays a role in disease resistance. The data show that SDH can positively regulate cotton Verticillium wilt. We found that the genes of the SDH1 subunit in cotton roots were significantly up-regulated after inoculation, especially GhSDH1-1, which peaked at 12 and $24 \mathrm{~h}$ post-infection. The study of $d s r 1$ suggested that the mutation of SDH1 reduced the catalytic efficiency of SDH, and the $\mathrm{Km}$ value as a binary switch of improving plant stress sensitivity and tolerance was lower, interrupting the SA signal pathway and reduced disease resistance 


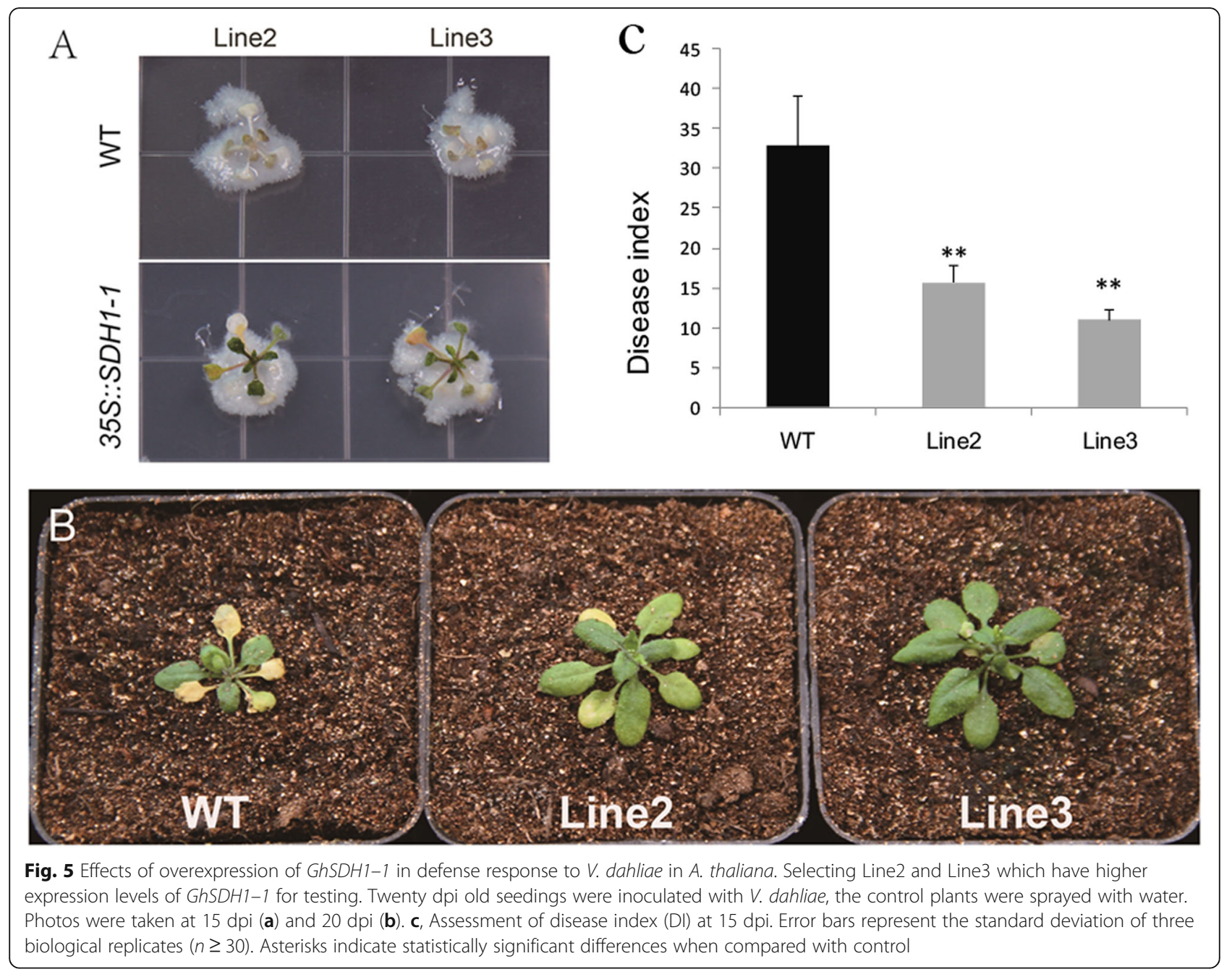

(Gleason et al. 2011; Belt et al. 2017). Using VIGS technology, we found that the content of fumaric acid decreased as expected when the gene was silenced, which may be due to the reduction of SDH catalytic efficiency. In addition, DI values and fungal recovery assay data confirmed that silencing of GhSDH1-1 significantly reduced the resistance of cotton to $V$. dahliae. When we tested the outbreak of reactive oxygen species in GhSDH1-1-silenced and control plants within $1 \mathrm{~h}$ after inoculation, the $\mathrm{H}_{2} \mathrm{O}_{2}$ content of silenced plants was lower than that of the control plants. An active oxygen burst is an important indicator of the initial stage of

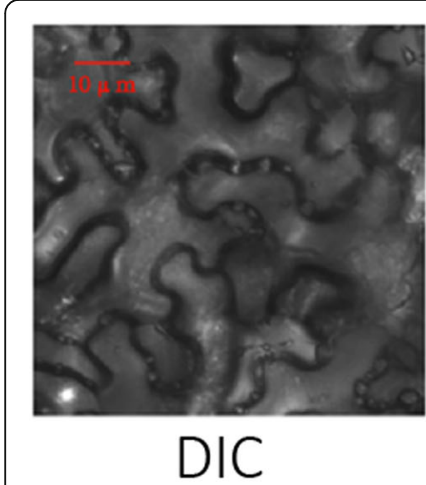

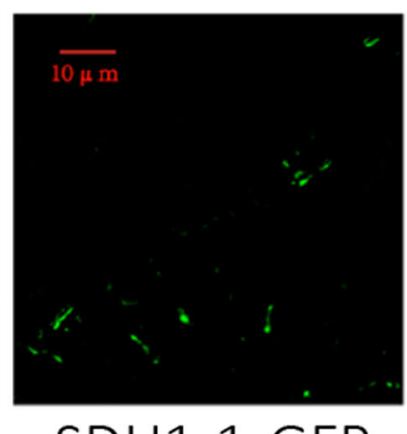

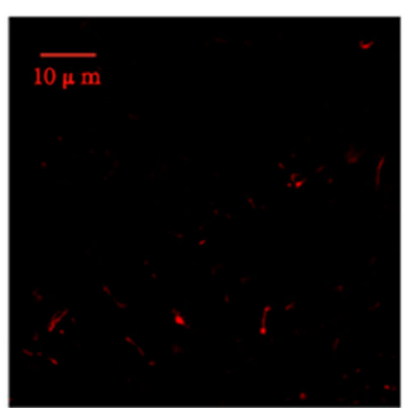

SDH1-1-GFP

Fig. 6 Co-localization of SDH1-1-GFP with mitochondria markers 
plant disease resistance. The in vitro experiments also confirmed that the control plants had more reactive oxygen bursts than the silenced plants. The content of NO in silenced cotton plants was slightly higher than that of control plants at the initial stage of infection, and then was lower than the control in the latter stage. The change in NO content may be due to the transient dynamic equilibrium between $\mathrm{NO}$ and $\mathrm{H}_{2} \mathrm{O}_{2}$ (Rao et al. 1997; Niu and Liao 2016). This reduction of ROS in GhSDH1-1-knockdown plants may be because the destruction of that, which the SA stimulation of SDH lead to reactions with oxygen to form ROS including superoxide $\left(\mathrm{O}_{2}^{-}\right)$(Belt et al. 2017). In GhSDH1-1-knockdown plants, the expression levels of $P P O, P O D$, and $P A L$ related to lignin synthesis were also disrupted. The expression of disease-related genes showed that the expression levels of $P P O, P O D$, and $P A L$ related to lignin synthesis were lower in silent plants than in control plants. Lignin is one of the main components of the cell wall. Generally, the higher the lignin content of the plant, the stronger the resistance to pathogens, especially of the vascular bundles infected by $V$. dahliae (Sun et al. 2013). These results indicate that with the silencing of GhSDH1-1, $\mathrm{H}_{2} \mathrm{O}_{2}$, NO, lignin synthesis and other important diseaseresistance processes are inhibited and significantly increase plant susceptibility to infection, thus supporting our conclusion of the important role of GhSDH1-1 in cotton disease resistance. Furthermore, we analyzed disease resistance traits in transgenic Arabidopsis plants based on DI values. The results indicate that WT plants showed more severe yellowing, chlorosis, and dysplasia than the overexpressed lines after inoculation. In summary, we found that GhSDH1-1 positively regulates cotton resistance to $V$. dahliae.

The use of different concentrations of SA to treat cotton and detection of expression of GhSDH1-1 helped further elucidate the relationship of GhSDH1-1 and the SA signaling pathway. The different concentrations of SA induced the expression of GhSDH1-1. The peak level occurred at $6 \mathrm{~h}$ after inoculation where the lowest concentration of SA induced the strongest expression of GhSDH1-1 (Yalpani et al. 1991). This evidence suggests that GhSDH1-1 may be associated with the SA signaling pathway. Moreover, it is demonstrated that the SA content was low in GhSDH1-1-silenced plants. SA is required for both local and systemic immunity against a wide range of the related genes of the pathogens $(\mathrm{Fu}$ et al. 2012; Kazan and Lyons 2014; Huang et al. 2016).

Three essential genes of the SA signaling pathway include NPR1, PR1, and PR3 (Häffner et al. 2014). Our results show that the expression levels of these genes were significantly decreased in the silenced plants, indicating that silencing GhSDH1-1 disrupted the response of the SA signaling pathway. Previous studies have demonstrated that Arabidopsis mutants of SDH1-1 have increased sensitivity to fungi and are more susceptible to disease because the SA-mediated downstream stress response was disrupted and mROS production reduced (Gleason et al. 2011; Edward et al. 2014; Huang et al. 2016; Belt et al. 2017). This is consistent with our findings, demonstrating that GhSDH1-1 interacts with the SA signaling pathway and positively regulates cotton resistance to Verticillium dahliae. Therefore, GhSDH1-1 is a promising candidate gene to improve the breeding of cotton varieties resistant to Verticillium wilt.

\section{Materials and methods}

\section{Plant materials and growth conditions}

Seeds of G. hirsutum Linn cv. 'Zhongzhimian 2' (a wiltresistant cultivar) were obtained from the Institute of Cotton Research of Chinese Academy of Agricultural Sciences. For disease assays, plants were grown in greenhouse at a $16 \mathrm{hday} / 8 \mathrm{~h}$ night cycle and $25^{\circ} \mathrm{C}$. The GhSDH1-1 overexpression vector (35S::GhSDH1-1) was inserted into wild-type (WT) A. thaliana Columbia ecotype (Col-0) plants. Arabidopsis seedlings were grown in a temperature- and light-controlled greenhouse between $22^{\circ} \mathrm{C}$ and $28^{\circ} \mathrm{C}$ with a $16 \mathrm{~h} / 8 \mathrm{~h}$ light cycle.

\section{Culturing of $V$. dahliae and inoculation of plants}

Verticillium dahliae strain V080 was cultured on potato dextrose agar (PDA) medium at $25^{\circ} \mathrm{C}$ for 5 days and then transferred to liquid Czapek's medium at $25^{\circ} \mathrm{C}$ for 6 days. The final concentration of spore suspension was adjusted to $1 \times 10^{10}$ conidia $\cdot \mathrm{L}^{-1}$ with sterile water (Zhang et al. 2015).

The first euphylla was fully expanded, and cotton seedlings were applyed slight damage to roots. And then $10 \mathrm{~mL}$ of the V080 conidia suspension $\left(1 \times 10^{10}\right.$ spores $\cdot \mathrm{L}^{-1}$ ) was injected into the soil. Control plants were inoculated with an equal volume of sterile distilled water. Similarly, after of growth in Arabidopsis, seedlings were grown in pots, and $10 \mathrm{~mL}$ of the V080 conidia suspension $\left(1 \times 10^{10}\right.$ spores. $\left.L^{-1}\right)$ was injected into the soil at 20 days after germination. While, seedlings on the medium (1/2 MS), were inoculated with $2 \mu \mathrm{L}$ of conidia suspension $\left(1 \times 10^{8}\right.$ conidia. $\left.\mathrm{L}^{-1}\right)$ after 2 weeks of germination (Gong et al. 2017).

\section{Transcription level analysis of genes by real-time quantitative polymerase chain reaction (RT-qPCR)}

Total RNA was extracted from wilt-resistant cultivars (Zhongzhimian 2) using an RNAprep Pure Plant Kit (Tiangen, Beijing, China) and the instructions of its manual. Total RNA was reversely transcribed into cDNA using the PrimeScript ${ }^{\text {tux }}$ II 1st Strand cDNA Synthesis Kit (Takara, Japan). Ubiquitin10 was used as an endogenous reference for normalization of cotton mRNA. All RT- 
qPCR primers were designed by the Primer Premier 5.0 program, and listed in Additional file 1: Table S1. RTqPCR was performed to determine the relative expression levels of several defense-related genes using SYBR Green PCR Master Mix (TIANGEN Biotech). The three-step method involved the following PCR conditions: 40 cycles of $95^{\circ} \mathrm{C}$ for $30 \mathrm{~s}, 95^{\circ} \mathrm{C}$ for $5 \mathrm{~s}$, and $60{ }^{\circ} \mathrm{C}$ for $30 \mathrm{~s}$. A minimum of three technical replicates were performed for each sample with at least three biological replicates. RT-qPCR analysis was determined using the $2^{-\Delta \Delta C t}$ methods ( $\mathrm{Hu}$ et al. 2018). Statistical significances were evaluated by $t$-test using SigmaPlot version 12.0. And, the confidence level of all analyses was set at $95 \%$ and $P$-values $<0.05$ were considered statistically significant.

\section{Generation of the virus-induced gene-silencing construct and pathogen inoculation}

The GhSDH1-1 fragment was amplified by PCR using 'Zhongzhimian 2' cDNA with the VGhSDH1-1-F/ VGhSDH1-1-R primers (Additional file 1: Table S1). The amplified fragments were subsequently cloned into the pTRV (TRV156) vector. The constructs (TRV:156, TRV:192, and TRV:SDH1-1) were then used to transform Agrobacterium tumefaciens strain GV3101 (Gao et al. 2011). An equivalent amount of TRV-156 vector was then injected into the cotyledons of 7-day-old cotton seedlings resistant to Verticillium wilt. After $24 \mathrm{~h}$ of incubation in the dark, cotton seedlings were grown in the greenhouse and inoculated with $V$. dahliae 10 days after infiltration with the vector.

\section{Arabidopsis thaliana transformation}

The full-length coding sequence of GhSDH1-1 (1 902 bp) containing $\mathrm{XbaI}$ and $\mathrm{SacI}$ linkers was cloned using the primers GhSDH1-1 (Table S1). For overexpression studies, the $35 \mathrm{~S}:: G h S D H 1-1$ vector was constructed by digesting the GhSDH1-1 coding sequence with XbaI and SacI (BioLabs, U.K). The digested sequence was then inserted into a modified pCAMBIA2300 (Kana, Japan) plant binary vector. Arabidopsis Col-0 was transformed by floral-dip method using $A$. tumefaciens strain GV3101 containing the GhSDH1-1 overexpression vector ( $\mathrm{Hu}$ et al. 2019). Transgenic seeds were then plated on Murashige and Skoog (MS) medium containing $0.1 \%$ Kanamycin to select positive transformants. The TransDirect Plant Tissue PCR Kit (TRAN, Beijing, China) and qPCR method were used to detect the T3 line with the transgene and the correct separation ratio. Only stable homozygous T3 lines that exhibited high levels of GhSDH1-1 expression were selected for further functional analysis.

\section{Salicylic acid treatments}

Cotton seedlings were grown in pots incubated in a greenhouse. They were sprayed with $1 \mathrm{mmol} \cdot \mathrm{L}^{-1}, 0.1$ $\mathrm{mmol} \cdot \mathrm{L}^{-1}$, or $0.01 \mathrm{mmol} \cdot \mathrm{L}^{-1} \mathrm{SA}$ at the foliar stage as described previously (Belt et al. 2017). Control plants were treated with sterile distilled water at the same $\mathrm{pH}$ and volume.

\section{Measurements of free salicylic acid, nitric oxide, $\mathrm{H}_{2} \mathrm{O}_{2}$, and fumaric acid levels}

The abundances of immune system-related molecules $\mathrm{SA}, \mathrm{H}_{2} \mathrm{O}_{2}$, NO and fumaric acid were monitored using different methods. The cotton root samples were collected at the corresponding time point after virusinduced gene silencing (VIGS) treatment, and stored in the $-80{ }^{\circ} \mathrm{C}$ refrigerator after liquid nitrogen treatment. The $\mathrm{NO}$ and $\mathrm{H}_{2} \mathrm{O}_{2}$ from root tissue were measured using a Quantitative Assay Kit (Nanjing Jiancheng, Beijing, China) (Gong et al. 2017). In addition, the roots sample was grinded, then added $2 \mathrm{~mL}$ of mobile phase, ultrasonic extraction for $30 \mathrm{~min}$, centrifuge at 5000 $\mathrm{r} \cdot \mathrm{min}^{-1}$ for $5 \mathrm{~min}$, and the supernatant was taken through a $0.22 \mu \mathrm{m}$ filter. Finally, the free SA and fumaric acid contents were determined via the high performance liquid chromatography (HPLC) system (Agilent 1 260) as previously described (Hu et al. 2019).

\section{Cell death assay}

The cell death assay performed is described by Gong et al. (2017). The cotton euphylla was taken at 7 days after inoculation with $V$. dahliae. Leaves were soaked in trypan blue dye ( $1 \mathrm{~g}$ phenol, $1 \mathrm{mg}$ Trypan blue, $1 \mathrm{~mL}$ lactic acid, and $1 \mathrm{~mL}$ glycerol dissolved in $1 \mathrm{~mL}$ sterile distilled water) and then boiling for $2 \mathrm{~min}$. After cooling to room temperature overnight, samples were soaked with a chloral hydrate solution $\left(1.25 \mathrm{~kg} \cdot \mathrm{L}^{-1}\right)$ for 3 days. Then observed the leaves with a stereo microscope and took photos.

\section{Verticillium dahliae recovery assay}

To confirm the effects of $V$. dahliae on cotton and $A$. thaliana plants, the stem fragments from the first stem node were analyzed. The stem samples collected from cotton and Arabidopsis plants were $5 \mathrm{~cm}$ and $3 \mathrm{~cm}$ long, respectively. The stem was cleaned with $75 \%$ ethaol, $3 \%$ sodium hypochlorite and sterile distilled water according to a previously described method (Zhang et al. 2011). Then cleaned stems were cut into seven sections. The stem fragment was placed on potato dextrose agar (PDA medium) in a plate and incubated at $25^{\circ} \mathrm{C}$. The number of stem segments that developed fungal growth indicated the degree of susceptibility of the plant to infection. 


\section{Analysis of disease index}

The assessment of disease was conducted according to Yuan et al. (2017). For cotton plants, the disease index (DI) was calculated according to the following formula: $\mathrm{DI}=[(\Sigma$ disease grade $\times$ number of infected plants $) /$ (total number of sampled plants $\times 4$ ) $] \times 100$. According to the symptoms observed from cotyledons and true leaves, the seedlings were divided into five grades $(0,1$, 2, 3 or 4). The disease severity of Arabidopsis plants was graded on a scale of $0-4$, and DI was calculated using the following formula (Gao et al. 2011): DI $=\left[\left(\sum\right.\right.$ disease grade $\times$ number of infected plants) / (total number of sampled plants) $\times 4$ ) $] \times 100$.

\section{Subcellular localization}

The full-length coding sequence of GhSDH1-1(without the stop codon) was inserted into the binary plant vector pBin-GFP, to constitute the transient expression vector SDH1-1-GFP. Then we transformed it to A. tumefaciens strain GV3101. The 3-week-old N. benthamiana plants at the 4-5 leave stage were infiltrated with the GV3101 mixture of SDH1-1-GFP and mt-rk (mitochondrial marker) via a syringe. The fluorescence in leaves was observed 48 h later (Pečenková et al. 2017).

\section{Conclusions}

Characterizing the function of GhSDH1-1 in cotton and Arabidopsis plants revealed that GhSDH1-1 positively regulates cotton resistance to Verticillium dahliae. Silencing of GhSDH1-1 significantly reduced the abundance of immune-related molecules and severely impaired the SA signaling pathway. Consequently, resistance of cotton to Verticillium wilt was significantly reduced. The overexpressed lines exhibited stronger resistance. These results provide new insights into the role of GhSDH1-1, confirming the important role of SDH in cotton against Verticillium wilt and its association with the SA signaling pathway.

\section{Supplementary information}

Supplementary information accompanies this paper at https://doi.org/10. 1186/s42397-020-00052-6.

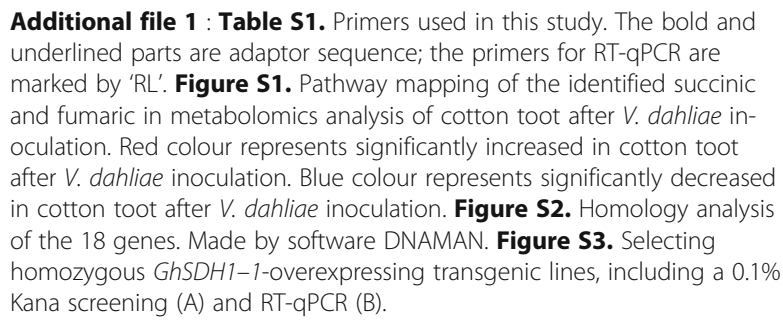

\section{Acknowledgments}

We thank Dr. XU, Xiangming at NIAB East malling research for his kind assistance with experiments and critical reading of the manuscript.

\section{Authors' contributions}

Feng $\mathrm{HJ}$ and Zhu HQ designed the experiments; Zhang XY and Zhao LH performed experiment and wrote the manuscript; Liu SC, Feng ZL, Wei F and Shi YQ assisted in some experiments and review the manuscript.

\section{Funding}

This work was supported by the National Natural Science Foundation of China (31701479).

\section{Availability of data and materials \\ Not applicable.}

Ethics approval and consent to participate

Not applicable.

\section{Consent for publication}

Not applicable.

\section{Competing interests}

The authors declare that the research was conducted in the absence of any commercial or financial relationships that could be construed as a potential conflict of interest.

\section{Author details}

${ }^{1}$ State Key Laboratory of Cotton Biology, Institute of Cotton Research of Chinese Academy of Agricultural Sciences, Anyang 455000, Henan, China. ${ }^{2}$ Zhengzhou Research Base, State Key Laboratory of Cotton Biology, School of Agricultural Sciences, Zhengzhou University, Zhengzhou 450001, China.

Received: 2 December 2019 Accepted: 30 March 2020

Published online: 06 May 2020

\section{References}

Belt K, Huang S, Thatcher LF, et al. Salicylic acid-dependent plant stress signaling via mitochondrial succinate dehydrogenase. Plant Physiol. 2017;173:2029-40. https://doi.org/10.1104/pp.16.00060.

Caarls L, Pieterse CMJ, Van W. How salicylic acid takes transcriptional control over jasmonic acid signaling. Front Plant Sci. 2015;6:170. https://doi.org/10.3389/ fpls.2015.00170.

Cai $\mathrm{Y}$, Xiaohong $\mathrm{H}, \mathrm{Mo}$ J, et al. Molecular research and genetic engineering of resistance to Verticillium wilt in cotton: a review. Afr J Biotechnol. 2009;8: 1684-5315.

Grant M, Lamb C. Systemic immunity. Curr Opin Plant Biol. 2006;9:414-20.

Chen Z, Silva H, Klessig D. Active oxygen species in the induction of plant systemic acquired resistance by salicylic acid. Science. 1993;262:1883-6. https://doi.org/10.1126/science.8266079.

Chen ZJ, Scheffler BE, Dennis E, et al. Toward sequencing cotton (Gossypium) genomes. Plant Physiol. 2007;145:1303-10. https://doi.org/10.1104/pp.107. 107672.

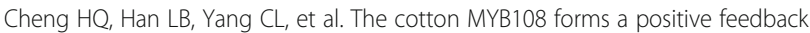
regulation loop with $C M L 11$ and participates in the defense response against to Verticillium dahliae infection. J Exp Bot. 2016;67:1935-50. https://doi.org/10. 1093/jxb/erw016.

Chouchani ET, Pell VR, Gaude E, et al. Ischaemic accumulation of succinate controls reperfusion injury through mitochondrial ROS. Nature. 2014;515:4315. https://doi.org/10.1038/nature13909.

Daayf F. Verticillium wilts in crop plants: pathogen invasion and host defence responses. Can J Plant Pathol. 2015;37:8-20. https://doi.org/10.1080/ 07060661.2014 .989908$.

Erdogan O, Sezener V, Ozbek N, et al. The effects of verticillium wilt (Verticilli7m dahliae Kleb.) on cotton yield and fiber quality. Asian J Plant Sci. 2006;5:86770. https://doi.org/10.3923/ajps.2006.867.870.

Fradin EF, Zhang Z, Juarez Ayala JC, et al. Genetic dissection of Verticillium wilt resistance mediated by tomato Ve1. Plant Physiol. 2009;150:320-32. https:// doi.org/10.1104/pp.109.136762.

Fu ZQ, Yan S, Saleh A, et al. NPR3 and NPR4 are receptors for the immune signal salicylic acid in plants. Nature. 2012;486:228-32. https://doi.org/10.1038/ nature11162.

Gao X, Wheeler T, Li Z, et al. Silencing GhNDR1 and GhMKK2 compromises cotton resistance to Verticillium wilt. Plant J. 2011;66:293-305. https://doi.org/10. 1111/j.1365-313X.2011.04491.x 
Gerik JS, Huisman OC. Study of field-grown cotton roots infected with Verticillium dahliae using an immunoenzymatic staining technique. Phytopathology. 1988;78:1174-8. https://doi.org/10.1094/phyto-78-1174.

Gleason C, Huang S, Thatcher LF, et al. Mitochondrial complex II has a key role in mitochondrial-derived reactive oxygen species influence on plant stress gene regulation and defense. Proc Natl Acad Sci U S A. 2011;108:10768-73. https:// doi.org/10.1073/pnas.1016060108.

Gong Q, Yang Z, Wang X, et al. Salicylic acid-related cotton (Gossypium arboreum) ribosomal protein GaRPL18 contributes to resistance to Verticillium dahliae. BMC Plant Biol. 2017;17:59. https://doi.org/10.1186/s12870-017-1007-5.

Häffner E, Karlovsky P, Splivallo R, et al. ERECTA, salicylic acid, abscisic acid, and jasmonic acid modulate quantitative disease resistance of Arabidopsis thaliana to Verticillium longisporum. BMC Plant Biol. 2014;14:85. https://doi. org/10.1186/1471-2229-14-85

Hu Q, Min L, Yang X, et al. Laccase GhLac1 modulates broad-spectrum biotic stress tolerance via manipulating phenylpropanoid pathway and jasmonic acid synthesis. Plant Physiol. 2018;176:1808-23. https://doi.org/10.1104/pp.17. 01628.

Hu Q, Zhu L, Zhang X, et al. GhCPK33 negatively regulates defense against Verticillium dahliae by phosphorylating GhOPR3. Plant Physiol. 2019;178:87689. https://doi.org/10.1104/pp.18.00737.

Huang S, Hans B, Ryan M, et al. Mitochondrial complex II of plants: subunit composition, assembly, and function in respiration and signaling. Plant J. 2019;98(3):405-17. https://doi.org/10.1111/tpj.14227.

Huang S, Millar AH. Succinate dehydrogenase: the complex roles of a simple enzyme. Curr Opin Plant Biol. 2013;16(3):344-9. https://doi.org/10.1016/j.pbi. 2013.02.007.

Huang S, Van AO, Schwarzlder M, et al. Roles of mitochondrial reactive oxygen species in cellular signalling and stress response in plants. Plant Physiol. 2016; 171(3):1551-9. https://doi.org/10.1104/pp.16.00166.

Jardim-Messeder D, Caverzan A, Rauber R, et al. Succinate dehydrogenase (mitochondrial complex II) is a source of reactive oxygen species in plants and regulates development and stress responses. New Phytol. 2015;208(3): 776-89. https://doi.org/10.1111/nph.13515.

Jiménez-Díaz RM, Cirulli M, Bubici G, et al. Verticillium wilt, a major threat to olive production: current status and future prospects for its management. Plant Dis. 2012;96(3):304-29. https://doi.org/10.1094/PDIS-06-11-0496.

Kazan K, Lyons R. Intervention of phytohormone pathways by pathogen effectors. Plant Cell. 2014;26:2285-309. https://doi.org/10.1105/tpc.114.125419.

$\mathrm{Li} A$, Zhang $\mathrm{R}$, Pan $\mathrm{L}$, et al. Transcriptome analysis of $\mathrm{H}_{2} \mathrm{O}_{2}$-treated wheat seedlings reveals a $\mathrm{H}_{2} \mathrm{O}_{2}$-responsive fatty acid desaturase gene participating in powdery mildew resistance. PLoS One. 2011;6(12):e28810. https://doi.org/ 10.1371/journal.pone.0028810

Li YB, Han LB, Wang HY, et al. The thioredoxin gbnrx1 plays a crucial role in homeostasis of apoplastic reactive oxygen species in response to Verticillium dahliae infection in cotton. Plant Physiol. 2016;170(4):2392-406. https://doi. org/10.1104/pp.15.01930.

Malik W, Ashraf J, lqbal MZ, et al. Molecular markers and cotton genetic improvement: current status and future prospects. Sci World J. 2014;2014: 607091. https://doi.org/10.1155/2014/607091.

Egbuta MA, Mclntosh S, Waters DL, et al. Biological importance of cotton byproducts relative to chemical constituents of the cotton plant. Molecules. 2017;22:93. https://doi.org/10.3390/molecules22010093.

Miao Y, Zhu L, Zhang X. Down regulation of cotton GbTRP1 leads to accumulation of anthranilates and confers resistance to Verticillium dahliae. J Cotton Res. 2019;2:19. https://doi.org/10.1186/s42397-019-0034-1.

Moreau M, Tian M, Klessig DF. Salicylic acid binds NPR3 and NPR4 to regulate NPR1-dependent defense responses. Cell Res. 2012;22:1631-3. https://doi. org/10.1038/cr.2012.100

Nie S, Yue H, Zhou J, Xing D. Mitochondrial-derived reactive oxygen species play a vital role in the salicylic acid signaling pathway in Arabidopsis thaliana. PLoS One. 2015;10:e0119853. https://doi.org/10.1371/journal.pone.0119853.

Niu L, Liao W. Hydrogen peroxide signaling in plant development and abiotic responses: crosstalk with nitric oxide and calcium. Front Plant Sci. 2016;7: 230. https://doi.org/10.3389/fpls.2016.00230.

Norman C, Howell KA, Millar AH, et al. Salicylic acid is an uncoupler and inhibitor of mitochondrial electron transport. Plant Physiol. 2004;134:492-501. https:// doi.org/10.1104/pp.103.031039.

Pečenková T, Pleskot R, Žárský V. Subcellular localization of Arabidopsis pathogenesis-related 1 (PR1) protein. Int J Mol Sci. 2017;18:825. https://doi. org/10.3390/ijms18040825.
Quinlan CL, Orr AL, Perevoshchikova IV, et al. Mitochondrial complex II can generate reactive oxygen species at high rates in both the forward and reverse reactions. J Biol Chem. 2012;287(32):27255-64. https://doi.org/10. 1074/jbc.M112.374629.

Ralph SJ, Moreno-Sánchez R, Neuzil J, Rodríguez-Enríquez S. Inhibitors of succinate: quinone reductase/complex II regulate production of mitochondrial reactive oxygen species and protect normal cells from ischemic damage but induce specific cancer cell death. Pharm Res. 2011;28: 2695-730. https://doi.org/10.1007/s11095-011-0566-7.

Rao MV, Paliyath G, Ormrod DP, et al. Influence of salicylic acid on $\mathrm{H}_{2} \mathrm{O}_{2}$ production, oxidative stress, and $\mathrm{H}_{2} \mathrm{O}_{2}$-metabolizing enzymes, salicylic acidmediated oxidative damage requires $\mathrm{H}_{2} \mathrm{O}_{2}$. Plant Physiol. 1997;115:137-49. https://doi.org/10.1104/pp.115.1.137.

Sattar MN, Kvarnheden A, Saeed M, Briddon RW. Cotton leaf curl disease-an emergingthreat to cotton production worldwide. J Gen Virol. 2013;94(4):695710. https://doi.org/10.1099/vir.0.049627-0.

Shaban M, Miao Y, Ullah A, et al. Physiological and molecular mechanism of defense in cotton against Verticillium dahliae. Plant Physiol Biochem. 2018; 125:193-204. https://doi.org/10.1016/j.plaphy.2018.02.011.

Sun $Q$, Jiang $H$, Zhu X, et al. Analysis of sea-island cotton and upland cotton in response to Verticillium dahliae infection by RNA sequencing. BMC Genomics. 2013;14:852. https://doi.org/10.1186/1471-2164-14-852.

Tretter L, Patocs A, Chinopoulos C. Succinate, an intermediate in metabolism, signal transduction, ros, hypoxia, and tumorigenesis. Biochimica et Biophysica Acta (BBA) - Bioenergetics. 2016;1857(8):1086-101. https://doi.org/ 10.1016/j.bbabio.2016.03.012.

Verma V, Ravindran P, Kumar P. Plant hormone-mediated regulation of stress responses. BMC Plant Biol. 2016;16:86. https://doi.org/10.1186/s12870-0160771-y.

Xu L, Zhu L, Tu L, et al. Differential gene expression in cotton defence response to Verticillium dahliae by SSH. J Phytopathol. 2011;159:606-15. https://doi.org/ 10.1111/j.1439-0434.2011.01813.x.

Yalpani N, Silverman P, Wilson TM, et al. Salicylic acid is a systemic signal and an inducer of pathogenesis-related proteins in virus-infected tobacco. Plant Cell. 1991;3(8):809-18. https://doi.org/10.1105/tpc.3.8.809.

Yan R, Liang C, Meng Z, et al. Progress in genome sequencing will accelerate molecular breeding in cotton (gossypium spp.). 3 Biotech. 2016;6:217. https:// doi.org/10.1007/s13205-016-0534-3.

Yankovskaya V, Horsefield R, Törnroth S, et al. Architecture of succinate dehydrogenase and reactive oxygen species generation. Science. 2003; 299(5607):700-4. https://doi.org/10.1126/science.1079605.

Yuan Y, Feng HJ, Wang LF, et al. Potential of endophytic fungi isolated from cotton roots for biological control against Verticillium wilt disease. PLoS One. 2017;12(1):e0170557. https://doi.org/10.1371/journal.pone.0170557.

Zhang K, Zhao P, Wang H, et al. Isolation and characterization of the GbVIP1 gene and response to Verticillium wilt in cotton and tobacco. J Cotton Res. 2019;2:2. https://doi.org/10.1186/s42397-019-0019-0.

Zhang $Y$, Wang $X$, Yang $S$, et al. Cloning and characterization of a Verticillium wilt resistance gene from Gossypium barbadense and functional analysis in Arabidopsis thaliana. Plant Cell Rep. 2011;30:2085-96. https://doi.org/10.1007/ s00299-011-1115-X.

Zhang YL, Li ZF, Feng ZL, et al. Isolation and functional analysis of the pathogenicity-related gene $V d P R_{3}$ from Verticillium dahliae on cotton. Curr Genet. 2015;61:555-66. https://doi.org/10.1007/s00294-015-0476-z.

Zhou Y, Sun L, Wassan GM, et al. Gbsobir1 confers Verticillium wilt resistance by phosphorylating the transcriptional factor GbbHLH171 in Gossypium barbadense. Plant Biotechnol J. 2018;17:152-63. https://doi.org/10.1111/pbi. 12954

\section{Ready to submit your research? Choose BMC and benefit from:}

- fast, convenient online submission

- thorough peer review by experienced researchers in your field

- rapid publication on acceptance

- support for research data, including large and complex data types

- gold Open Access which fosters wider collaboration and increased citations

- maximum visibility for your research: over $100 \mathrm{M}$ website views per year

At BMC, research is always in progress.

Learn more biomedcentral.com/submissions 